\title{
Morphological Analysis of Articularis Genus and Involvement in Muscle Synchronicity with Vastus Intermedius
}

\author{
Análisis Morfológico del Músculo Articular de la Rodilla y su Participación \\ en la Sincronicidad Muscular con el Músculo Vasto Intermedio
}

Hiroto Kobayashi $^{1}$; Yuta Takano²; Takuma Yuri ${ }^{3}$; Saori Yoshida ${ }^{1}$; Katsuhiko Suzuki ${ }^{2}$, Yoshiro Kiyoshige ${ }^{2}$ \& Akira Naito $^{1}$

KOBAYASHI, H.; TAKANO, Y.; YURI, T.; YOSHIDA, S.; SUZUKI, K.; KIYOSHIGE, Y. \& NAITO, A. Morphological analysis of articularis genus and involvement in muscle synchronicity with vastus intermedius. Int. J. Morphol., 36(3):859-863, 2018.

SUMMARY: The articularis genus, which lies under the vastus intermedius, has been regarded as part of the quadriceps femoris. However, they are well known to have different function because their respective origins and insertions are mutually distinct. These muscles are considered to work almost simultaneously when the knee is extended. The electromyogram has been used to demonstrate muscle co-contraction. However, the articularis genus is deeper than other muscles. Moreover, it is difficult to analyze it by surface electromyogram. The relative proportions of muscle fiber types and the characteristics of these fiber types are important determinants of the surface electromyogram. Furthermore, biomechanical analysis of AG has remained unclear. This study investigated the ratio of muscle fiber types in these muscles. Muscle samples from seven human cadaveric specimens were used with application of immunofluorescence double staining. Results show that in the vastus intermedius and articularis genus, the percentage of Type I fibers was significantly higher than that of Type II fibers. No significant difference was found in the mean percentages of Type I and Type II fiber types. The percentages of Type I and Type II fibers in articularis genus muscle were correlated positively to the percentage in the vastus intermedius. These results suggest that similar muscle fiber compositions of these muscles might reflect their contraction during the same active phase of knee extension, despite their different functions.

KEY WORDS: Articularis genus; Vastus intermedius; Muscle fiber type; Cadaver; Immunohistochemistry.

\section{INTRODUCCIÓN}

The quadriceps femoris (QF), the great extensor muscle of the leg covering almost all the front and sides of the femur (Standring, 2004), comprises four parts: rectus femoris (RF), vastus lateralis (VL), vastus medialis (VM), and the vastus intermedius (VI). Nerves stemming from the femoral nerve distribute to each muscle and control muscles generally. The QF function is extension of the knee, but the origins and insertions of each muscle mutually differ. Consequently, their strict functions are known to differ slightly.

The articularis genus (AG) lies deep, adjacently to VI. Reportedly, it is present in $80-100 \%$ of individuals (DiDio et al., 1967, 1969; Ahmad et al., 1975; Puig et al., 1996; Roth et al., 2004). It originates from the anterior surface of the distal aspect of the femur and inserts into the proximal and posterior aspects of the suprapatellar bursa. The last branch of the femoral nerve for VI is known to distribute to AG after passage through VI; moreover, AG and QF are supplied by the same nerve (Kimura \& Takahashi, 1987; Standring). Some studies have demonstrated the difficulty of distinguishing AG from VI on MRI in terms of their neural branching (Kimura \& Takahashi) and their bundles (Woodley et al., 2012). However, the function of AG apparently differs from that of VI because the respective origins and insertions of AG and VI differ. Reportedly, the function of $\mathrm{AG}$ is to elevate the capsule and synovial membrane of the knee during knee extension, and to prevent their entrapment between the patella and the femur (DiDio et al., 1967, 1969; Ahmad et al.).

Human skeletal muscles can be categorized into two main types (Ross \& Pawlina, 2010). Type I fibers, so-called slow twitch muscle fibers, are well known to be difficult to fatigue and to have weak occurrence tension. Such fibers are well suited for persistent contraction necessary to remain

\footnotetext{
${ }^{1}$ Department of Anatomy and Structural Science, Faculty of Medicine, Yamagata University, 2-2-2 Iida-nishi, Yamagata 990-9585, Japan.

${ }^{2}$ Department of Physical Therapy, Yamagata Prefectural University of Health Sciences, 260 Kamiyanagi, Yamagata 990-2212, Japan.

${ }^{3}$ Department of Occupational Therapy, Yamagata Prefectural University of Health Sciences, 260 Kamiyanagi, Yamagata 990-2212, Japan.
} 
upright for a long time. Type II fibers, called fast twitch muscle fibers, can emit maximum contractility in contrast to Type I fibers, but they are easily fatigued. For QF, a difference in fiber type composition between VL and VI (Edgerton et al., 1975) is known to exist, even though it remains unknown whether this is the case for all distal QF, or not. Linssen et al. (1991) described that the relative proportions of muscle fiber types and the characteristics of these fiber types are important determinants of surface EMG. However, it is difficult to analyze AG by surface EMG. Biomechanical analysis of AG has remained far from clear. Therefore, we consider that their ratio might reflect the character or function of muscles and hypothesized that the fiber type composition of AG would differ from that of VI because AG purportedly functions differently than QF. This study specifically examined the ratios of muscle fiber types in these muscles.

\section{MATERIAL AND METHOD}

Cadaveric specimens. Seven human cadaveric specimens (six males, one female) embalmed by $10 \%$ formalin solution for tissue excision were obtained from Yamagata University. Mean age of specimens was $81.57 \pm 6.61$ (range: $76-93$ ) years old. According to available death certificate, none had any history of neuromuscular disease. Specimens were dissected to expose the right VI and AG following the conventional method. All procedures were performed in accordance with the institutional guidelines, and approved by the research ethical committee at Yamagata University (\#315).

Tissue sampling and slide preparation. Samples of muscle tissue, each approximately 10-20 mm in length and 5-10 $\mathrm{mm}$ in depth, were collected from right VI and AG of each specimen. All samples were taken from the center of each muscle along the midpoint of the fiber bundles, and each sample was post fixed overnight in Bouin's solution without acetic acid at $4{ }^{\circ} \mathrm{C}$. Tissues were then dehydrated in a graded ethanol series, and embedded in Paraplast embedding media (Sigma, St Louis, MO, U.S.A.). Cross sections of each sample were cut at a thickness of $5 \mathrm{~mm}$, and sections were extended onto the slides (Matsunami Glass Ind., Ltd. Osaka, Japan) at $40{ }^{\circ} \mathrm{C}$ for overnight.

Immunofluorescence double staining. The sections were deparaffinized in xylene and hydrophilized in a graded ethanol series. Subsequently, the samples were incubated with antigen retrieval agent $\mathrm{pH} 9.0$ (Nichirei Co., Tokyo, Japan) at $95{ }^{\circ} \mathrm{C}$ for 20 minutes and rinsed with phosphate buffered saline (PBS, $0.02 \mathrm{M}$ sodium phosphate buffer, 0.15 $\mathrm{M}$ sodium chloride, $\mathrm{pH}$ 7.4). Blocking solution consisting of $2 \%$ bovine serum albumin (Sigma) in PBS was applied at $37{ }^{\circ} \mathrm{C}$ for 30 minutes. Two primary antibodies, anti-fast myosin skeletal heavy chain (1: 1,000, \#ab91506, Abcam, Cambridge, UK) and anti-slow myosin skeletal heavy chain (1: 10,000, \#ab11083, Abcam), were used to label myosin heavy chains of Type I and Type II fibers respectively. Sections were incubated overnight at $37{ }^{\circ} \mathrm{C}$ with the primary antibody. The secondary antibody, anti-mouse $\operatorname{IgG}(\mathrm{H}+\mathrm{L})$ highly Cross-Adsorbed Secondary Antibody Alexa Fluor 488 (1: 400, \#A-11029, Thermo Fisher Scientific Inc. MA, U.S.A.) and anti-rabbit IgG $(\mathrm{H}+\mathrm{L})$ highly Cross-Adsorbed Secondary Antibody Alexa Fluor 568 (1: 400, \#A-11036, Thermo Fisher Scientific Inc.), were used for an hour at 37 ${ }^{\circ} \mathrm{C}$. After washing in PBS, slides were mounted with fluorescent mounting medium (\#S3023, Agilent Technologies, CA, U.S.A.) and stored at $4{ }^{\circ} \mathrm{C}$ until observation. As a negative control of immunohistochemistry, nearly adjacent sections were incubated without the primary antibody, and then incubated with the secondary antibody. No labeling was confirmed in these control sections.

Taking images and counting fiber type. Images of prepared tissue sectionswere captured with a DFC7000T (Leica Microsystems GmbH, Wetzlar, Germany) attached to DM2500LED microscope (Leica), and images were then saved in a high resolution Tiff format. A total of three to five images were taken of both muscle in part of each specimen, such that an average of one thousand fibers were photographed. Each fiber was counted on the Adobe Photoshop (Adobe Systems Inc., CA, U.S.A.), and the mean percentages of Type I and Type II fibers in the fiber population of muscles part of each specimen were calculated. The hybrid fibers were excluded because of the number of that was little in this study.

Statistical analysis. The data was statistically analyzed by one-way ANOVA followed by the student $\mathrm{T}$ test and linear regression, as appropriate, using StatView software (Hulinks, Inc., Tokyo, Japan). The P value was set at $<0.01$.

\section{RESULTS}

Morphology of muscle fibers. The photomicrographs of VI (Figs. 1 A-C) and AG (Figs. 1 D-F) were shown in Figure 1. Type I fibers (Figs. 1A and 1D) were observed as circular or polygonal shapes. By contrast, Type II fibers (Figs. $1 \mathrm{~B}$ and $1 \mathrm{E})$ exhibited an irregular shape. Although the staining intensity in each fiber showed little difference, Type I and Type II fibers were little overlapped in merged images (Figs. 1C and 1F). Furthermore, the cross-sectional area of Type II fibers was apparently smaller than that of Type I 

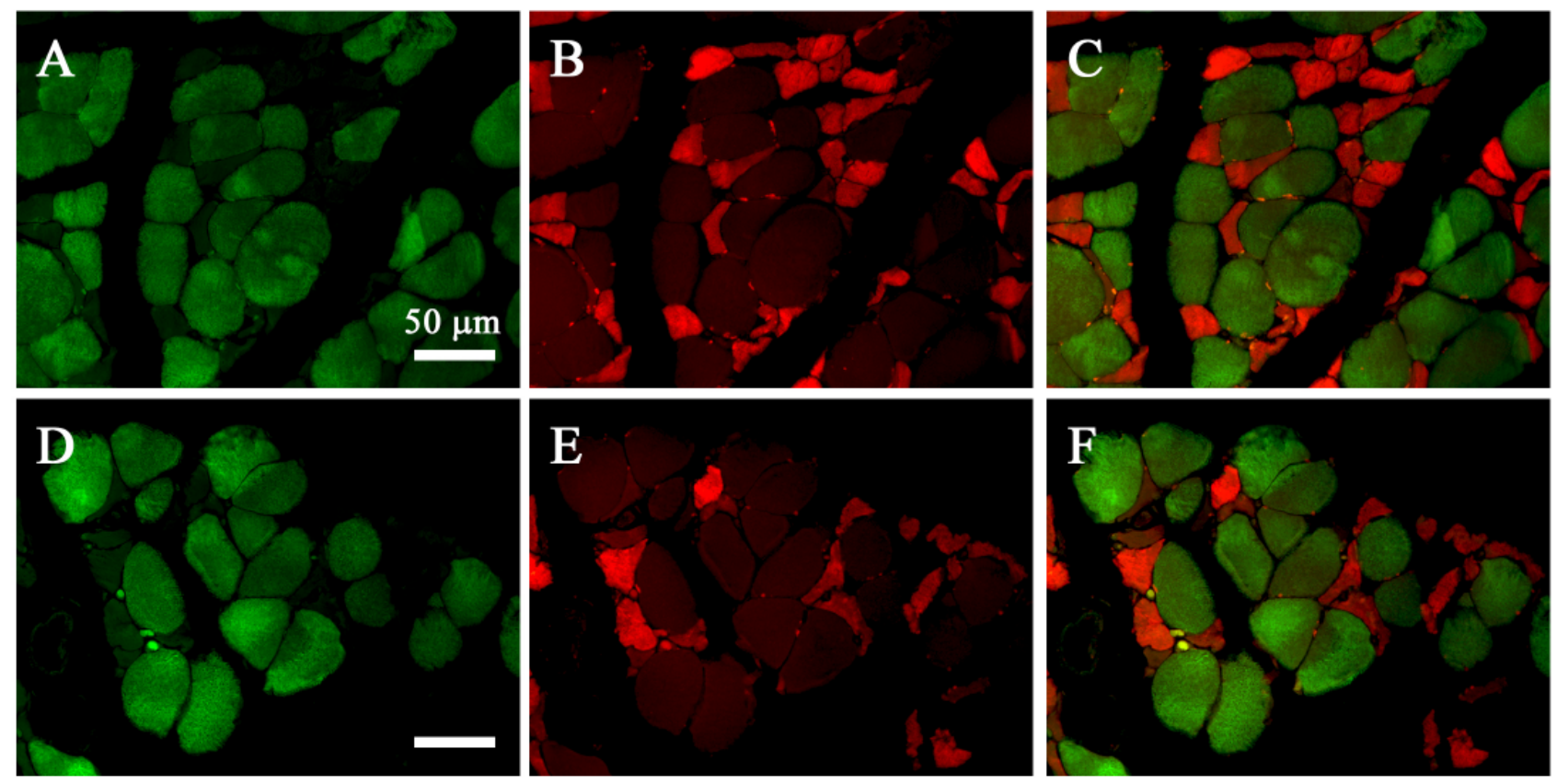

Fig. 1. Photomicrographs demonstrating Type I fibers (A and D), Type II fibers (B and E) and merge (C and F) in VI (A-C) and AG (DF). Both of muscles showed complementary immunohistochemical staining of Type I and Type II fibers. It seemed that there was apparently no difference in the size of each fiber between AG and VI. Magnification is x400.

A

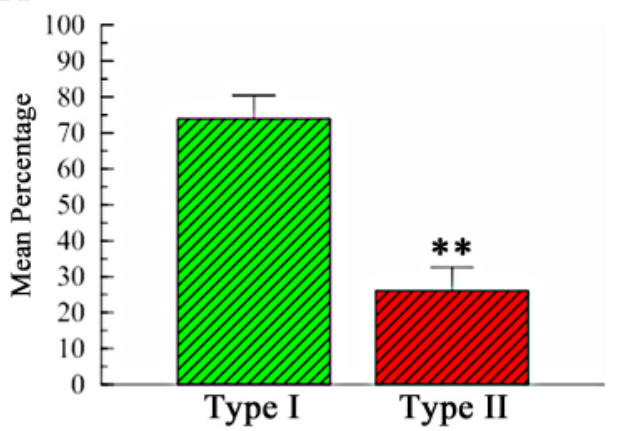

B

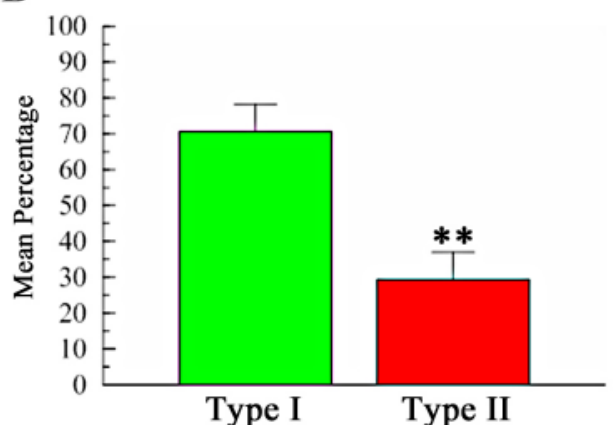

Fig. 2. Comparison of mean percentage of each fiber type in VI (A) and AG (B). In VI, mean percentage of Type I and Type II fibers are $73.90 \pm 1.38 \%$ and $26.10 \pm 1.38 \%$. In AG, mean percentage of Type I and Type II fibers are $70.64 \pm 1.80 \%$ and $29.36 \pm 1.80 \%$. Type I fibers were higher percentage than Type II fibers in each muscle. Each column shows the mean, and bar represents the standard error in each group. $* * \mathrm{P}<0.01$ analyzed by the student $\mathrm{T}$ test.

fibers. It appears, however, that there were no differences in the sizes of fibers between AG and VI.

Percentage of fiber type. Mean percentage of fiber types in VI (Fig. 2A) and AG (Fig. 2B) are showed. In VI, the percentage of Type I fibers was significantly higher than that of Type II fibers $(\mathrm{P}<0.01)$. The mean percentage of Type I fibers is $73.90 \pm 1.38 \%$, ranging from 60.30 to $85.47 \%$ in VI.
However, the percentage of Type I fibers is significantly higher than Type II fibers in AG $(\mathrm{P}<0.01)$. The mean percentage of Type I fibers is $70.64 \pm 1.80 \%$, ranging from 57.18 to $83.17 \%$ in AG. A comparison of VI and AG shows no significant difference in the mean percentages of fiber types both Type I (Fig. 3A) and Type II (Fig. 3B). In regression analysis, the percentage of Type I and Type II fibers in AG are positively correlated with the percentage of VI $(\mathrm{P}<0.01, \mathrm{R} 2=0.743)$. 

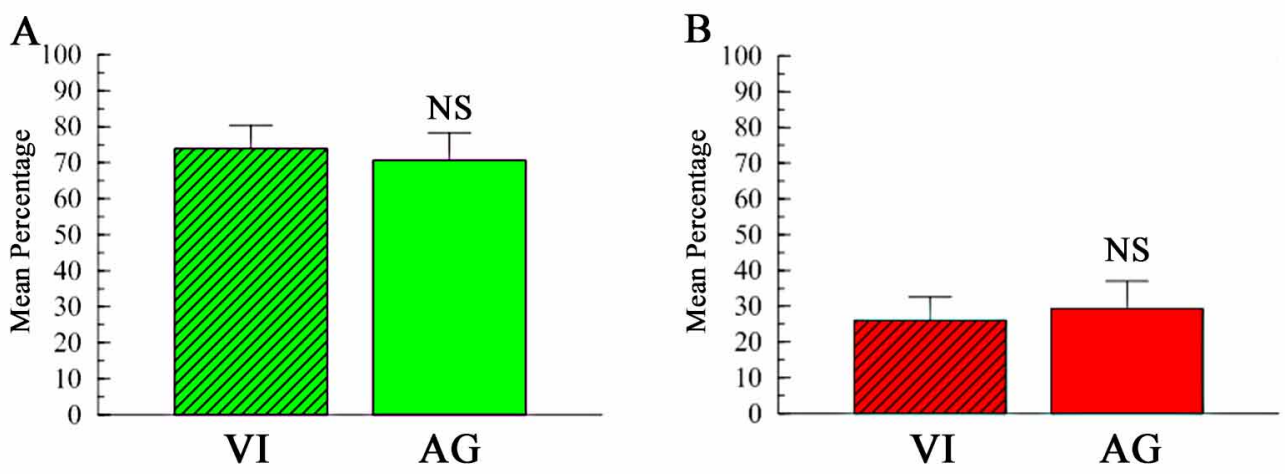

Fig. 3. Comparison of mean percentage of each muscle in Type I fibers (A) and Type II fibers (B). In Type I fibers, mean percentage of VI and AG are $73.90 \pm 1.38 \%$ and $70.64 \pm 1.80 \%$. In Type II fibers, mean percentage of VI and AG are $26.10 \pm 1.38 \%$ and $29.36 \pm 1.80 \%$. There was no significant difference in the ratio of fiber types of each muscle. Each column shows the mean, and bar represents the standard error in each group. NS: no significant analysis by the student T test.

\section{DISCUSSION}

Reports of earlier studies describe a difference in fiber type composition between VL and VI (Edgerton et al.). We inferred that the difference of ratios might reflect the muscle character or function. Actually, AG is known to have the function of preventing the capsule from being pinched during leg extension. Also, VI has the function of knee extension (DiDio et al., 1967, 1969; Ahmad et al.; Standring). It is true that both are completely different functions. However, no significant difference was found in the ratio of the percentage of each fiber type between VI and AG in this study (Figs. 2 and 3). Furthermore, the ratio of muscle fibers between VI and AG was found to have a strong positive correlation. Reportedly, the relative proportions of muscle fiber types and the characteristics of these fiber types are important determinants of the surface EMG (Linssen et al.). Analyzing AG by surface EMG is difficult because AG lies under the VI. Synchronicity between AG and VI has not been proved, but the similar muscle fiber composition of these two muscles might reflect their contraction during the same active phase of knee extension. Woodley et al. reported the proportions of fiber types between the AG and VI in two cadavers. They also described that the results of one cadaver might have been more reliable than those for the other cadaver, which appeared atrophic in some areas. However, the number of their samples was insufficient. Their research results therefore did not compare statistically. Consequently, the ratios of muscle fiber compositions of these muscles clarified in this study constitute a new finding. We used only right muscles in this study. However, Woodley et al. reported that the proportion in the right limb muscle of each cadaver was like that in the corresponding left limb muscle. It was inferred that no laterality exists in the composition of muscle fiber type.
Edgerton et al. reported that VI has $47 \pm 3 \%$ of Type I fibers and $53 \pm 3 \%$ of Type II fibers. These results differed greatly from those of our study (Fig. 2A). The mean age of specimens was $81.57 \pm 6.61$ years old in this study: this was categorized as a very old group (80 years and older) in an earlier study (Lexell, 1995). In addition, the area of Type II fibers was apparently smaller than that of Type I (Fig. 1). The area and number of muscle fibers, particularly for Type II, is known to decrease and show atrophy with age (Lexell). Type I fibers are regarded as too difficult to change with aging (Lexell; Nilwik et al., 2013). Consequently, it is reasonable to infer that atrophy occurs because of aging in the samples of this study and that our results differed from those of preceding studies. Muscular atrophy is degeneration caused by aging. Reportedly, it occurs in various muscles. Lexell described changes in the sizes of muscle fiber types with increasing age in VL and the tibialis anterior muscle. The tibialis anterior muscle exhibited atrophy of Type II fibers, as did VL (Jakobsson et al., 1990). This result suggests the possibility of occurrence of similar atrophy associated with the aging of each muscle. Therefore, it can be speculated that similar atrophy occurs in both AG and VI. The muscle cross sectional area, total number of fibers, mean Type II fiber area (but not Type I) and relative area of Type II fibers decreased with aging. Furthermore, the relation between age and measures of the arrangement of Type I and Type II fibers showed the same tendency. From that result, we infer that muscle fibers undergo continuous denervation and reinnervation because of the accelerated loss of motor neurons in the spinal cord (Lexell). In other words, the change of neurodegeneration with aging of Type I and Type II fibers displays a similar tendency. It is inferred that similar aging 
changes are followed because AG and VI are under the similar innervation. Although atrophy occurs with aging, the ratios of the muscle fibers of both muscles are similar. Results show no difference in the ratio of muscle fibers in AG and VI, although the values might differ from those in younger people. Results of the present study suggest that both muscles have synchronicity or same active phase during knee motion, even though their functions differ. This report is the first of a study comparing AG and VI muscle fiber types. Further research is required, such as echo analysis in living humans.

ACKNOWLEDGEMENTS. We are deeply grateful to laboratory members for giving us constructive comments and warm encouragement. Funding from the Annual Plan of Yamagata University (grant number DAY2609) is gratefully acknowledged.

KOBAYASHI, H.; TAKANO, Y.; YURI, T.; YOSHIDA, S.; SUZUKI, K.; KIYOSHIGE, Y. \& NAITO, A. Análisis morfológico del músculo articular de la rodilla y su participación en la sincronicidad muscular con el músculo vasto intermedio. Int. J. Morphol., 36(2):859-863, 2018.

RESUMEN: El músculo articular de la rodilla, que se encuentra cubierto por el músculo vasto intermedio, se ha considerado como parte del músculo cuádriceps femoral. Sin embargo, es sabido que tienen diferentes funciones debido a que sus respectivos orígenes e inserciones son mutuamente distintas. Se considera que estos músculos trabajan de forma casi simultánea cuando la rodilla está extendida. El electromiograma se ha usado para demostrar la contracción muscular. Sin embargo, el músculo articular de la rodillas es más profundo que otros músculos. Además, es difícil analizarlo por electromiograma de superficie. Las proporciones relativas de los tipos de fibras musculares y las características de estos tipos de fibras son importantes determinantes del electromiograma de superficie. Además, el análisis biomecánico de músculo articular de la rodilla no ha sido claro. Este estudio investigó la proporción de tipos de fibras musculares en estos músculos. Se usaron muestras musculares de siete cadáveres humanos con la aplicación de doble tinción de inmunofluorescencia. Los resultados muestran que en los músculos articular de la rodilla y vasto intermedio, el porcentaje de fibras de Tipo I fue significativamente mayor que el de las fibras de Tipo II. No se encontraron diferencias significativas en los porcentajes medios de los Tipo I y Tipo II. Los porcentajes de fibras Tipo I y Tipo II en el músculo articular de la rodilla se correlacionaron positivamente con el porcentaje en el músculo vasto intermediario. Estos resultados sugieren que las composiciones de las fibras musculares similares de estos músculos podrían reflejar su contracción durante la misma fase activa de la extensión de la rodilla, a pesar de sus diferentes funciones.

PALABRAS CLAVE: Músculo articular de la rodilla; Músculo vasto intermedio; Tipo de fibra muscular; Cadáver; Inmunohistoquímica.

\section{REFERENCES}

Ahmad, I. Articular muscle of the knee--articularis genus. Bull. Hosp. Joint Dis., 36(1):58-60, 1975.

DiDio, L. J.; Zappalá, A. \& Carney, W. P. Anatomico-functional aspects of the musculus articularis genus in man. Acta. Anat. (Basel), 67(1):1-23, 1967.

DiDio, L. J.; Zappalá, A.; Cardoso, A. D. \& Diaz, R. A. Musculus articularis genus in human fetuses, newborn and young individuals. Anat. Anz., 124(2):121-32, 1969.

Edgerton, V. R.; Smith, J. L. \& Simpson, D. R. Muscle fibre type populations of human leg muscles. Histochem. J., 7(3):259-66, 1975.

Jakobsson, F.; Borg, K. \& Edström, L. Fibre-type composition, structure and cytoskeletal protein location of fibres in anterior tibial muscle. Comparison between young adults and physically active aged humans. Acta. Neuropathol., 80(5):459-68, 1990.

Kimura, K. \& Takahashi, Y. M. articularis genus. Observations on arrangement and consideration of function. Surg. Radiol. Anat., 9(3):231-9, 1987.

Lexell, J. Human aging, muscle mass, and fiber type composition. $J$. Gerontol. A Biol. Sci. Med. Sci., 50 Spec. No.:11-6, 1995.

Linssen, W. H.; Stegeman, D. F.; Joosten, E. M.; Binkhorst, R. A.; Merks, M. J.; ter Laak, H. J. \& Notermans, S. L. Fatigue in type I fiber predominance: a muscle force and surface EMG study on the relative role of type I and type II muscle fibers. Muscle Nerve, 14(9):829-37, 1991.

Nilwik, R.; Snijders, T.; Leenders, M.; Groen, B. B.; van Kranenburg, J.; Verdijk, L. B. \& van Loon, L. J. The decline in skeletal muscle mass with aging is mainly attributed to a reduction in type II muscle fiber size. Exp. Gerontol., 48(5):492-8, 2013.

Puig, S.; Dupuy, D. E.; Sarmiento, A.; Boland, G. W.; Grigoris, P. \& Greene, R. Articular muscle of the knee: a muscle seldom recognized on MR imaging. A. J. R. Am. J. Roentgenol., 166(5):1057-60, 1996.

Ross, M. H. \& Pawlina, W. Histology: A Text and Atlas - With Correlated Cell and Molecular Biology. $5^{\text {th }}$ ed. Philadelphia, Wolters Kluwer Health, 2010.

Roth, C.; Jacobson, J.; Jamadar, D.; Caoili, E.; Morag, Y. \& Housner, J. Quadriceps fat pad signal intensity and enlargement on MRI: prevalence and associated findings. A. J. R. Am. J. Roentgenol., 182(6):1383-7, 2004.

Standring, S. Gray's Anatomy: The Anatomical Basis of Clinical Practice. $39^{\text {th }}$ ed. Edinburgh, Elsevier Churchill Livingstone, 2004.

Woodley, S. J.; Latimer, C. P.; Meikle, G. R. \& Stringer, M. D. Articularis genus: an anatomic and MRI study in cadavers. J. Bone Joint Surg. Am., 94(1):59-67, 2012.

Corresponding author:

Hiroto Kobayashi

Department of Anatomy and Structural Science

Faculty of Medicine

Yamagata University

2-2-2 lida-nishi

Yamagata 990-9585

JAPAN

E-mail: kob-h@med.id.yamagata-u.ac.jp 